Titulo do Trabalho

\title{
ATIVIDADES DE EDUCAÇÃO AMBIENTAL DO PARQUE ESTADUAL DE PORTO FERREIRA EM COMEMORAÇÃO AO ANO INTERNACIONAL DAS FLORESTAS.
}

\author{
Nome do Autor (a) Principal

\section{Sonia Aparecida de Souza}

Nome (s) do Coautor (a) (s)

\section{Suélen Rigon; João Paulo Ferrari de Oliveira}

Instituição ou Empresa

\section{Instituto Florestal / Fundação Florestal - Parque Estadual de Porto Ferreira.}

Instituição (s) de Fomento

\section{Parque Estadual de Porto Ferreira.}

\author{
E-mail de contato \\ pe.pferreira@fflorestal.sp.gov.br
}

RESUMO: Para comemorar o Ano internacional das Florestas, o Parque Estadual de Porto Ferreira desenvolveu de forma participativa com órgãos municipais de Educação, Cultura e Turismo e com o Conselho Consultivo atividades educativas, interpretativas e culturais. As estratégias utilizadas na Semana do Meio Ambiente foram reuniões com professores, palestras temáticas, vídeos ambientais e estudo do meio para a comunidade escolar na Trilha das Árvores Gigantes. Na Semana da Árvore, palestras, vídeos ambientais, interpretação da natureza e um seminário para estudantes e comunidade em geral. As diferentes atividades contribuíram para o conhecimento das características dos recursos naturais, da biodiversidade e com divulgação do Parque como unidade de conservação de florestas nativas do município de Porto Ferreira e região, estreitando a sua relação com a comunidade local. 
Palavras-chave: Planejamento participativo. Estudo do Meio e Interpretação da Natureza.

\section{INTRODUÇÃO}

A Educação Ambiental é um processo por meio dos quais o indivíduo e a coletividade constroem valores sociais, conhecimentos, habilidades, atitudes e competências voltadas para a conservação do meio ambiente. Deve estar presente, de forma articulada, em todos os níveis e modalidades do processo educativo, em caráter formal e não-formal (BRASIL, 1999).

A Educação Ambiental não-formal é definida como ações e práticas educativas voltadas à sensibilização da coletividade sobre as questões ambientais e à sua organização e participação na defesa da qualidade do meio ambiente, cabendo ao poder público em nível federal, estadual e municipal incentivar a sensibilização da sociedade para a importância das unidades de conservação (BRASIL, 1999).

Os Parques são unidades de conservação de proteção integral que têm entre outros, os objetivos de desenvolver atividades de educação e interpretação ambiental, recreação em contado com a natureza e turismo ecológico (BRASIL, 2000).

Segundo SANTOS et al. (2000) em uma unidade de conservação a prática da Educação Ambiental tem objetivos de divulgação de informações e conhecimentos científicos para possibilitar a conscientização da comunidade local e se referir a educação na, sobre e para o ambiente.

De acordo com VASCONCELLOS (2006) as áreas naturais protegidas oferecem oportunidades únicas para a reaproximação das pessoas aos ambientes naturais, aliando conhecimento, reflexões, desafios, afetividade, curiosidade, imaginação e noção de pertencimento.

Um dos objetivos do uso público nas unidades de conservação de proteção integral é propiciar o desfrute da natureza, despertando a consciência crítica para a importância da conservação e contribuir para a proteção das unidades (SÃO PAULO, 2008).

Nesse contexto está o Parque Estadual de Porto Ferreira - PEPF com 611,55 hectares criado em 1962 por conservar florestas nativas na região nordeste do interior do Estado de São Paulo. 
O Programa de Uso Público do PEPF e os subprogramas educação ambiental, interpretação da natureza, ecoturismo e eventos, têm em comum, o objetivo de sensibilizar e conscientizar a comunidade sobre a importância da biodiversidade existente na unidade, utilizando estratégias de palestras temáticas, exposições, trilhas interpretativas, estudos do meio, jogos, atividades lúdicas e seminários (TABANEZ et al., 2003).

Nas últimas décadas vários estudos apontam a importância das florestas nativas para a qualidade de vida no planeta.

A Organização das Nações Unidas declarou 2011 o Ano Internacional das Florestas, com o tema "Florestas para o Povo", enfatizando o papel fundamental das pessoas para a gestão, conservação e exploração sustentável das florestas, sendo essas vitais para a sobrevivência e o bem estar dos que povoam o planeta Terra.

\section{OBJETIVO GERAL}

- Desenvolver atividades educativas, interpretativas e culturais em comemoração ao Ano Internacional das Florestas.

\section{OBJETIVOS ESPECÍFICOS}

- Desenvolver atividades educativas na Semana do Meio Ambiente para professores e estudantes das séries finais do ensino fundamental sobre a importância das florestas e do PEPF, e

- Oferecer atividades na Semana da Árvore para a comunidade escolar e em geral, enfatizando o PEPF como estratégia de conservação de florestas nativas do município de Porto Ferreira e região.

\section{METODOLOGIA}

\subsection{Semana do Meio Ambiente}


Nessa semana adotou-se a estratégia de estudo do meio na Trilha das Árvores Gigantes para professores e estudantes de duas escolas municipais de Porto Ferreira EMEF Prof. José Gonso e EMEF Profa. Noraide Mariano, uma vez que, essa configura um processo educativo com atividades antes, durante e após as visitas.

Os trabalhos iniciaram com reuniões com o Departamento de Educação e com professores em HTPC - Horário de Trabalho Pedagógico Coletivo para apresentação da proposta e convite para desenvolvimento do tema Parque/Floresta de forma transversal.

No dia 01/06/2011 foram apresentadas palestras com o tema "Meio Ambiente, importância das Florestas e do Parque Estadual de Porto Ferreira" nas referidas escolas e houve também a disponibilização de materiais da unidade para os professores.

Para o estudo do meio na Trilha das Árvores Gigantes, foi elaborado um roteiro, e disponibilizadas lupas e termômetros para observações, medições dos diferentes ambientes e da diversidade de espécies vegetais e animais, utilizando a dinâmica do $\mathrm{m}^{2}$. A Trilha é um dos principais espaços pedagógicos do PEPF. Tem 3,5 km de extensão (ida e volta) com percurso no Cerradão, Floresta Estacional Semidecidual Mata de Porte Arbóreo Alto com Alta densidade de Jequitibás e Mata Ciliar. Possui sinalização, placas e painéis interpretativos.

\subsection{Semana da Árvore}

A semana foi organizada a partir de reuniões de planejamento com membros do Conselho Consultivo do PEPF; com o Departamento Municipal de Educação, Cultura e Turismo. A divulgação foi efetuada por meio de convites às escolas, universidades, instituições afins e imprensa local; fixação de faixas no Parque, na cidade e distribuição de cartazes em pontos estratégicos.

As atividades foram elaboradas com base na interpretação ambiental onde são utilizadas trilhas, centros de interpretação, palestras, publicações, painéis e exposições (TABANEZ et al., 2003; VASCONCELLOS, 2006), desenvolvidas no Parque e no auditório municipal "Esaltino Casemiro".

No dia 19/09/2011 o evento "Conhecendo a Floresta" no PEPF contou com apresentações culturais da Fanfarra da Escola "EMEF Prof. Sud Menucci" e do Coral 
Municipal Coro Et Laboro; caminhada monitorada e interpretação da natureza na Trilha das Árvores Gigantes; piquenique e apresentação musical do Projeto Ponto de Cultura; distribuição de materiais do Parque - folder, folheto sobre o Dia da Árvore e de mudas de espécies nativas.

Entre os dias 20/09 a 30/09/2011 participaram das atividades interpretativas estudantes e professores do projeto "Lugares de Aprender" com apresentação de palestra sobre o PEPF; vídeo sobre a importância das florestas quanto aos aspectos ambientais; caminhada monitorada na Trilha das Árvores Gigantes, plantio simbólico de muda na área de uso público e entrega de uma muda para plantar nas escolas.

No dia 29/09/2011 no Seminário sobre Florestas realizado no Anfiteatro Municipal Esaltino Casemiro participaram estudantes, professores, e representantes de diferentes segmentos da comunidade de Porto Ferreira.

O Seminário contou com a apresentação do Vocal Vozes da Natureza com músicas próprias e outras relacionadas ao tema; palestras ministradas por Técnicos da unidade, membros do Conselho Consultivo, e pesquisadora referentes ao PEPF com os temas: - Programa de Pesquisa, Ameaças à Conservação; Relação e Interdependência entre aves e florestas, Estrutura da Vegetação, Ações institucionais da Polícia Ambiental e o Ano Internacional das Florestas.

Os trabalhos desenvolvidos por técnicos do Parque, alunos e professores da UNESP - Rio Claro; os animais silvestres taxidermizados e posters de paisagens do Centro de Visitantes formaram a exposição.

\section{RESULTADOS}

\subsection{Semana do Meio Ambiente}

As reuniões em HTPC atingiram 23 professores. No Parque, o estudo do meio foi realizado com 56 alunos e duas professoras da $7^{\text {a }}$ série da EMEF Prof. José Gonso e com 54 alunos e dois professores da $8^{a}$. série da EMEF Profa. Noraide Mariano. 
Após as visitas ao Parque, os alunos da EMEF Prof. José Gonso confeccionaram cartazes para demonstrar os conhecimentos sobre a unidade, com ênfase na importância das florestas do município de Porto Ferreira.

Os alunos da EMEF Profa. Noraide Mariano desenvolveram atividades de forma multidisciplinar associando os conhecimentos sobre o Parque aos conteúdos de ciências, português, artes e informática por meio de produção de textos, cartazes, pesquisas e elaboração de Power-point, abordando entre outros, os temas de interação fauna e flora e o rio Mogi-Guaçu, conforme um dos princípios da PNEA - abordagem articulada das questões ambientais locais, regionais, nacionais e globais (BRASIL, 1999).

\subsection{Semana da Árvore}

Participou desse evento o total de 370 pessoas, sendo 279 no "Conhecendo a Floresta" no PEPF e 91 no "Seminário sobre Florestas" no anfiteatro municipal.

As atividades desenvolvidas atingiram professores, estudantes e comunidade em geral, conforme ações previstas do Plano de Manejo.

Segundo os membros do conselho consultivo foi o início de um processo de aproximação do Parque com a comunidade em geral e devem se repetir.

A partir dos eventos em comemoração ao Ano Internacional das Florestas, o PEPF foi convidado à participar de outras atividades educativas, sociais e culturais no Município de Porto Ferreira como o Dia da Criança, o Sacode a Praça e encerramento do ano letivo de uma escola com diretores, coordenadores, professores, alunos e pais, integrando educação, meio ambiente e cultura.

\section{CONSIDERAÇÕES FINAIS}

O planejamento participativo com membros do conselho consultivo e órgãos municipais de Porto Ferreira possibilitou e viabilizou o desenvolvimento das atividades educativas, interpretativas e culturais em comemoração ao Ano Internacional das Florestas para alunos, professores e comunidade, configurando-se em uma estratégia 
ímpar às ações de educação ambiental do PEPF. Todos os funcionários e servidores do Parque contribuíram de alguma maneira para viabilizar as referidas atividades.

A atuação dos membros do Conselho Consultivo das universidades na Semana da Árvore agregou valores e possibilitou a socialização de conhecimentos técnicos, à comunidade.

De maneira geral os objetivos foram atingidos e as atividades possibilitaram o conhecimento das características da biodiversidade, dos recursos naturais e a divulgação do Parque Estadual de Porto Ferreira como estratégia de conservação de florestas nativas do município de Porto Ferreira e região, estreitando a relação da comunidade local com a unidade.

\section{REFERÊNCIAS BIBLIOGRÁFICAS}

BRASIL. Lei no 9.795, de 27 de abril de 1999. Dispõe sobre a Educação Ambiental, institui a Política Nacional de Educação Ambiental e da outras providências. Disponível em: <http://www.lei.adv.br/9795-99.htm>. Acesso em 12 jan. 2011.

BRASIL. Lei no 9.985, de 18 de julho de 2000. Dispõe sobre o Sistema Nacional de Unidades de Conservação da Natureza (SNUC). Brasília, DF: MMA/SBF, 32 p. 2000.

SANTOS, J.E. et al. A práxis da Educação Ambiental aplicada a uma Unidade de Conservação (Estação Experimental de Luiz Antonio, SP). In: SANTOS, J. E \& PIRES, J.S.R (ed.) Estudos Integrados em Ecossistemas Estação Ecológica de Jataí. 1 Editora RiMa, São Carlos, p. 149159. 2000.

SÃO PAULO. Lei no 12.780 de 30 de novembro de 2007. Institui a Política Estadual de Educação Ambiental. D.O.E., 1 dez 2007. Seção I, p. 1 - 3.

SÃO PAULO. Resolução SMA no 59 de 27 de agosto de 2008. Regulamenta os procedimentos administrativos de gestão e fiscalização do uso público nas Unidades de Conservação de proteção integral do Sistema Estadual de Florestas do Estado de São Paulo, e dá outras providências. Disponível em: <http://iscoti.com/download resoluçao \%20SMA59\%202008.pdf>.Acesso em: 20 dez.2008.

TABANEZ, M. F. et al. Plano de Manejo do Parque Estadual de Porto Ferreira. São Paulo: $\mathrm{O}_{2}$ Estúdio Web, 2003. 1 CD-ROM.

VASCONCELOS, J. M. O. Educação e Interpretação Ambiental em Unidades de Conservação. Cadernos de Conservação (3) 4. 2006. 